\title{
SOBRE LA TERCERA CONSIDERACIÓN INTEMPESTIVA Y EL ESTADO GRIEGO: LA CRÍTICA POLÍTICO-CULTURAL DE NIETZSCHE A LA MODERNIDAD
}

On Third Untimely Meditations and The Greek State: Nietzsche's politicalcultural Criticism of Modernity

\author{
José Emilio Esteban Enguita
}

Universidad Autónoma de Madrid

\begin{abstract}
RESUMEN: El propósito fundamental de este artículo es mostrar la intempestividad del joven Nietzsche como una crítica cultural y política a la modernidad a partir del análisis e interpretación de dos textos fundamentales de este periodo en lo que respecta a la mencionada crítica: Consideraciones intempestivas III: Schopenhaner educador y El Estado griego.

Palabras clave: crítica político-cultural - modernidad-intempestividad - joven Nietzsche
\end{abstract}

ABSTRACT: This paper aims to show the young Nietzsche's intempestivity as a cultural and political criticism of Modernity. For this purpose, we will analyze and interpret two main works connected with the already mentioned criticism: Untimely meditations III: Schopenhauer as an educator and The Greek State.

Keywords: Cultural and political criticism - Modernity - Intempestivity - Young Nietzsche

En su autobiografía intelectual, Nietzsche comienza el comentario que hace a sus cuatro Consideraciones intempestivas refiriéndose al carácter guerrero y agresivo de su crítica a la modernidad, a la cultura de su época y a su querida y odiada Alemania: «Las cuatro Intempestivas son íntegramente belicosas. Demuestran que yo no era ningún 'Juan el Soñador', que me gusta desenvainar la espada acaso también que tengo peligrosamente suelta la muñeca» ${ }^{94}$. El rasgo virulento de la crítica filosófica no perderá fuerza en su caso con el paso del tiempo, sino que, por el contrario, se intensificará, terminando por comparar la actividad del filósofo con la del trabajador especializado en tareas de demolición. Hay que participar en el derribo de todo lo que se está desmoronando, de los viejos ideales, de los valores supremos que están perdiendo su hegemonía. El pathos intempestivo, como crítica, se manifiesta de modo inmediato como un ir «contra» su tiempo y todo lo que significa. Pero ni sólo ni principalmente Nietzsche juega a la contra: si así fuera, estaría apresado por el espíritu reactivo de los «esclavos de la moral», un espíritu vengativo y trufado de resentimiento que sólo puede afirmarse a sí mismo después de negar al otro, al «malvado» (böse),

\section{4. $\mathrm{EH}, \mathrm{KSA}$ VI 316.}


evidentemente ${ }^{95}$. No le agradaría en absoluto a este filósofo ser encuadrado en el grupo de los reaccionarios por el hecho de atacar a su tiempo y a los creyentes en el dogma del progreso. La intempestividad como estado de ánimo y rasgo determinante del carácter tiene para Nietzsche, como motor y fundamento de su movimiento crítico, la autoafirmación de un «sí mismo» que a su vez afirma la vida «tal cual es». Como nos dice de Más allá del bien y del mal en Ecce homo, sólo después de la tarea del «sí» representada por su Zaratustra cabe la tarea del decir «no", de llevar a la práctica la negación, «la transvaloración misma de los valores anteriores, la gran guerra, - el conjuro de un día de la decisión» ${ }^{96}$. Y asimismo, la negación contenida en la crítica a la modernidad en su llamada «época de juventud» se sostiene en el substrato positivo de su concepción trágica del mundo o, dicho con otras palabras, en la afirmación de la vida simbolizada por la milagrosa unión de Dioniso y Apolo. Expondremos la guerra declarada por el Nietzsche de El nacimiento de la tragedia y de las Intempestivas a la modernidad, una guerra cuya arma principal es la crítica cultural, a la que acompaña de un modo coherente y necesario la crítica política, y lo haremos tomando como elementos nucleares dos textos: la Tercera intempestiva y El Estado griego.

\section{MODERNIDAD: DISGREGACIÓN DE LA VIDA HUMANA Y HUNDIMIENTO DE LA CULTURA}

Como escritos de combate, el ciclo intempestivo, que en sus aspectos fundamentales ya está prefigurado en los últimos diez parágrafos de El nacimiento de la tragedia, tiene como objeto de crítica y como enemigo a batir la modernidad desde el punto de vista privilegiado de la cultura, lo que en la Primera consideración intempestiva denomina "el catecismo de las 'ideas modernas'»" de modo ejemplar en el «cultifilisteo» D. Strauss. El «espíritu de la ciencia»"${ }^{98}$, es decir, los presupuestos metafísico-morales que constituyen el contenido del cientificismo - siendo el historicismo una modalidad suya-, que sirven como fundamento de la cultura moderna y que se remontan al punto de inflexión histórico representado por Sócrates, es el edificio que la piqueta crítica debe derruir, tarea a la que se dedican especialmente las dos primeras Intempestivas. Las dos últimas, que prosiguen con la crítica a la cultura moderna, tienen sin embargo como finalidad principal sentar las bases para la edificación de una verdadera cultura, una cultura que supere el carácter ruinoso y menesteroso de la Época Moderna, utilizando para este fin, como «ejemplos» del ideal concebido por Nietzsche, las figuras de Schopenhauer y Wagner. Pero es en la Intempestiva sobre Schopenhauer donde Nietzsche anuda de un modo brillante los motivos críticos contra la cultura moderna, el esbozo positivo de una cultura superior y el

95. Cf. GM, KSA V 270-71.

96. EH, KSA VI 350

97. DS, KSA I 175.

98. Por «espíritu de la ciencia» Nietzsche entiende «aquella creencia, aparecida por vez primera en la persona de Sócrates, en la posibilidad de sondear la naturaleza y en la universal virtud curativa del saber» (GT, KSA I 111). 
horizonte metafísico que les ilumina, que no es otro que el de El nacimiento de la tragedia.

¿Cómo interpreta Nietzsche la modernidad en esta Intempestiva? Como «médico y policía de la cultura», y puesto que su época está gravemente enferma, su interpretación es un diagnóstico que describe los síntomas y señala la causa del grave mal que padece. Los rasgos negativos de su tiempo dejan una sola alternativa al futuro: la barbarie o una cultura superior. El hombre moderno, su cultura y su época se describen por el joven Nietzsche mediante una conjunción de atributos negativos repartidos en todos sus textos. En esta obra, aquí y allá, aparecen estas características que nos muestran la pobreza y mendacidad de la época y que son reflejadas en la pulida y perfecta superficie especular que es el pensamiento de Schopenhauer. Por ejemplo: en esta época no dominan hombres vivos sino meras apariencias que son reproducciones de la impersonal y anónima «opinión pública ${ }^{99}$; los modernos, en comparación con los griegos y los romanos, y aunque sólo sea en cuestiones relativas a la educación, revelan un semblante miserable ${ }^{100}$; además, son los hijos de una época empobrecida y agotada; el alma moderna se desenvuelve bajo el malestar producido por el conflicto entre un cristianismo cohibido e hipócrita y una tendencia apocada y culpable al naturalismo de la Antigüedad, generándose una oscilación que la condena a la confusión, la tristeza y la esterilidad ${ }^{101}$; o, por último, la naturaleza deforme y extravagante del hombre moderno, que se disfraza con falacias peligrosas y antinaturales como «progreso», «cultura general», «nacional», «Estado moderno» «lucha cultural» ${ }^{102}$.

Pero es en el epígrafe cuarto de esta Intempestiva donde Nietzsche dibuja magistralmente en tres páginas el cuadro clínico de la modernidad y señala la naturaleza de la enfermedad ${ }^{103}$. Allí, los síntomas de la enfermedad moderna, no muy distintos de los señalados por filósofos o científicos sociales de la época (piénsese, por ejemplo, en Coleridge o Carlyle sin su conservadurismo, en Comte y los santsimonianos sin su sociologismo, o en Marx sin su socialismo), son cinco: la disolución de la religión tradicional como poder espiritual y social; la política como lucha desnuda por el poder y el Estado como fin supremo de la existencia; la ascensión irresistible del homo oeconomicus y el despreciable capitalismo que absorbe todas las energías del hombre utilizándolas en una actividad racionalmente orientada al lucro; la práctica desmesurada de la ciencia que todo lo disuelve -incluso el mito en que se asienta- $\mathrm{y}$ acaba dañando a la vida, y, por último, la corrupción de las clases cultas, que se convierten en apologistas del orden existente pervirtiendo su misión de custodiar la formación y la cultura. Tres de ellos, poco después, funcionan también como causas que extienden la enfermedad: el egoísmo del Estado, de los propietarios y de los científicos-eruditos - a los que hay que añadir el egoísmo de los que cultivan las «bellas formas», que no aparece en el texto citado- manipulan la cultura rebajándola a mera servidora de sus propósitos ${ }^{104}$.

99. Cf. SE, KSA I 338.

100. Cf. SE, KSA I 343.

101. Cf. SE, KSA I 345.

102. Cf. SE, KSA I 407.

103. Cf. SE, KSA I 366-368.

104. Cf. SE, KSA I 387-394. 
El mal que corroe la vida moderna se describe, además, mediante metáforas extraídas de la física: la modernidad es la época de los «átomos», del «caos atómico», y de fuerzas salvajes, elementales y groseras, de fuerzas antagónicas y sin una medida que las regule y concilie. Dicho con otras palabras: el hombre y su mundo se le presentan a Nietzsche en un tiempo caracterizado por la disgregación en grado sumo, la fragmentación en todos sus ámbitos, la disolución de cualquier orden. Y la otra cara de la descomposición está formada por esas conmociones terribles que han de surgir de las entrañas de la modernidad: la lucha entre sí y por el predominio de las fuerzas que han quedado desligadas, la violencia surgida de la anarquía, la destrucción indiscriminada de la revolución «atómica». En suma: la barbarie que se cierne fatídicamente sobre la época.

Para Nietzsche, la causa de la enfermedad está clara: un total exterminio y desarraigo de la cultura. Arrancada del suelo de la vida del que recibe su alimento y explotada por potencias que la reducen a la esclavitud, que la rebajan a ser un medio de fines ajenos y contrarios a su ser, la cultura, en la modernidad, está en trance de desaparición. La «cultura» moderna, en la medida en que en esta época aún se puede hablar de cultura y no de un ridículo impostor que se hace pasar por ella, se encuentra vitalmente exangüe y consumida, careciendo de las fuerzas necesarias para cumplir su papel rector en la existencia humana. Para comprender la afirmación de que la verdadera causa de la enfermedad que azota su tiempo es cultural y que, por tanto, el resto de los males que se pueden observar son síntomas o efectos mórbidos derivados de aquélla, se precisa desentrañar los significados del término "cultura» para Nietzsche.

En un lugar de esta Intempestiva Nietzsche utiliza la expresión «physis transfigurada». Cuando Schopenhauer se libera de la perniciosa influencia de la época, descubre en su interior al genio, revelándose entonces «el reino de la physis transfigurada» ${ }^{105}$. Al final de la Segunda consideración intempestiva utiliza una expresión parecida: frente al concepto romano de cultura, decorativo, mero ornato de la vida, se encuentra el verdadero, el griego: la cultura es «una physis nueva y perfeccionada, sin interior ni exterior, sin fingimiento ni convencionalismo, la cultura como una armonía entre el vivir, el pensar, el aparentar y el querer» ${ }^{106}$. La cultura como transfiguración de la physis define el significado metafísico de la cultura, el más importante, pero no el único.

El significado metafísico de la cultura se encuentra en la «consideración previa» que Nietzsche introduce en el parágrafo quinto de esta Intempestiva y se desgrana en éste y en los dos siguientes. Este inciso filosófico que interrumpe el curso de la exposición reproduce los principales contenidos metafísicos de $E l$ nacimiento de la tragedia. Simplificándola en exceso y contemplándola desde aquella obra, la metafísica de artista puede resumirse en dos ideas: en primer lugar, la finalidad de la Naturaleza es la producción del genio, pues mediante él logra su redención (autoconocimiento y autoperfeccionamiento); en segundo lugar, la «verdadera cultura» es aquella que, haciendo consciente la meta de la Naturaleza, promueve el cumplimiento de la misma. A la luz de estas dos ideas, la interpretación metafísica de la cultura afirma que ésta, en tanto que physis transfigurada, nos revela el reencuentro de la Naturaleza consigo misma a través

105. SE, KSA I 363.

106. HL, KSA I 334. 
de la mediación simbólica efectuada por el genio, el punto máximo de elevación de la Naturaleza (redención) en el que ésta se ve reflejada y perfeccionada en el espíritu (arte, filosofía y religión) y éste se reconoce como naturaleza redimida. No es la cultura, sino el genio quien produce la reunificación simbólica de la Naturaleza y, por tanto, la meta que persigue con ciego afán. Pero la cultura es inseparable del genio, y esto en dos sentidos: por un lado, la cultura es producida por el genio y, en tanto que tal, es la mediación simbólica «objetivada» que logra la reunificación; por otro, es el seno materno del genio: sin ella, que constituye su suelo nutricio y su atmósfera propicia, éste no puede crecer y cumplir con éxito su tarea.

El significado metafísico de la cultura es el principal porque nos muestra su esencia, el ser physis transfigurada. Y también porque proporciona el criterio para establecer una jerarquía entre las culturas, otorgando la máxima excelencia y perfección a la cultura trágica, pues sólo mediante ella la Naturaleza alcanza su redención suprema. Pero no es el único ni, en lo que respecta a la crítica de la modernidad, el más relevante. Desde luego, si en la Época Moderna la cultura agoniza, entonces queda frustrado el propósito de la Naturaleza; si en ella la cultura deja de ser el fin supremo y se la rebaja al convertirla en medio, queda incapacitada para llevar a cabo su misión. Sin embargo, la enfermedad moderna no consiste tanto en la insuficiencia de su cultura para la protección del genio, como en la disolución del orden cultural y su consecuencia: la precipitación en la barbarie. Entre la cultura perfecta y la barbarie se encuentran en Nietzsche unos estados culturales «imperfectos» que, aunque no satisfacen plenamente la meta de la Naturaleza, impiden, sin embargo, la regresión absoluta del hombre a la esfera de la animalidad. Éste es el gran peligro de su tiempo. Y aquí es donde hay que considerar un segundo significado del término «cultura» para Nietzsche, un significado «mundano», «empírico», «fenoménico», en el cual se desvela en todo su alcance la enfermedad moderna.

Una buena entrada a este otro significado de la palabra «cultura» nos la proporciona Nietzsche en la definición que nos da en la Primera consideración intempestiva y que repetirá en la Segunda: «La cultura es ante todo la unidad de estilo artístico en todas las manifestaciones vitales de un pueblo. El saber muchas cosas y el haber aprendido muchas cosas no son, sin embargo, ni un medio necesario de la cultura ni tampoco una señal de cultura y resultan perfectamente compatibles, si es preciso, con la antítesis de la cultura, con la barbarie, es decir, con la carencia de estilo y con la mezcolanza caótica de todos los estilos» ${ }^{107}$. En principio, puede apreciarse en esta definición dos características que, sobre la cultura, el joven Nietzsche comparte con una poderosa tradición intelectual alemana que se remonta al siglo XVIII y que sobrevivirá hasta la Segunda Guerra Mundial: en primer lugar, la cultura, enfrentada a la civilización, se circunscribe a la esfera de lo producido por el espíritu, es decir, al arte, la religión y la filosofía principalmente; $y$, en segundo, la cultura se convierte en aquello que determina la identidad de un pueblo y le singulariza, diferenciándole de los demás ${ }^{108}$. Pero lo que aquí nos interesa no es la polémica cultura/civilización en la

107. DS, KSA I 163.

108. Sobre esta idea de cultura en Alemania, su génesis social y su oposición a la idea de civilización, cf. N. Elias, El proceso de la civilización. Investigaciones sociogenéticas y psicogenéticas, 
que el joven Nietzsche participaría activamente y de la que después, a partir de Humano, demasiado humano, renegaría. Lo relevante de esta definición consiste en que nos muestra claramente el porqué de la enfermedad moderna, su causa, que no puede ser otra que cultural. La modernidad es un tiempo de crisis porque carece de la unidad fundamental que sólo puede otorgar la cultura a individuos, pueblos y épocas. De ahí el caos, la fragmentación y la disolución que muestra la época. Y de ahí también el hecho de que ni del Estado ni de la economía ni de la ciencia, las fuerzas hegemónicas que pretenden edificar una nueva unidad a partir de las ruinas de su tiempo, pueda esperarse éxito alguno en este terreno, pues sólo la cultura tiene la potestad de legislar en la cuestión del sentido de la existencia.

De acuerdo con este segundo significado del término "cultura», ésta se determina como el entramado de ideas y valores (ilusiones, al fin y al cabo) mediante las cuales el ser humano se orienta en la existencia y se mantiene en ella. La cultura es lo que aporta, en definitiva, el horizonte de sentido gracias al cual puede vivir como ser humano y no sólo como animal inteligente. Por ello sólo la cultura puede aportar el principio o los principios que otorgan unidad y cohesión a la vida humana en su aspecto individual, social e histórico. Puesto que ella y sólo ella dirime las cuestiones básicas relativas a los fines de la existencia, todos los demás aspectos del mundo humano deben subordinarse a ella. Sea «mejor» o «peor» desde un punto de vista metafísico, tan sólo la cultura puede generar los mitos sin los cuales el ser humano no es más que una especie biológica.

La otra cara de la fragmentación y el caos es la violencia, cuya expresión moderna es la «revolución atómica». Las múltiples fuerzas, liberadas de la presión del viejo orden que las mantenía unidas, luchan entre sí persiguiendo el predominio. La riada, incontenible, desborda los cauces e inunda las riberas llevándose todo a su paso. Esta descripción, plagada de brillantes metáforas, es de una época aparentemente "pacífica» y «civilizada», de «el jardín imaginado de la cultura liberal $\rangle^{109}$, del tiempo en el cual muchos profetizaron el fin de las guerras, el supremo mal político, y de la pobreza, el gran azote de la humanidad. Sin embargo, a la luz de lo acontecido en el siglo xx, parece ser que Nietzsche vislumbró las terribles «conmociones» que se estaban gestando en las entrañas de su tiempo y que forzosamente tendrían que aflorar. Sin la unidad producida por la vigencia incondicional de una cultura, a pesar de compromisos coyunturales, de afinidades y acuerdos de conveniencia, la violencia anárquica irrumpirá una y otra vez, con variable intensidad. Estados, iglesias, clases, individuos, concepciones del mundo, etc., todos se encuentran en un estado de guerra efectiva o larvada. Históricamente, Nietzsche encuentra la causa de este estado de cosas en la descomposición de la autoridad moral que la Iglesia ejercía sobre el poder temporal, la cual mantenía unidas las «fuerzas elementales y salvajes» ahora desencadenadas. Estructuralmente, y por lo tanto aplicable a cualquier época histórica, la causa radica en la disolución del orden cultural, en el exterminio de la cultura característico de la modernidad. Y, por último, cabe aducir una razón «ontológica»: sin el poder profiláctico y regulador de la cultura, la lucha por la existencia, una invariante de la vida humana y de la vida en gene-

México/Madrid/Buenos Aires: FCE, 1987, pp. 57-82.

109. G. Steiner, En el castillo de Barba Azul, Barcelona: Labor, 1977, p. 11. 
ral, derivada del ser de la Naturaleza o, lo que es lo mismo, del de la Voluntad, acaba interpretando en el teatro del mundo una obra abominable y salvaje. Por ello, el correlato de la cultura en el plano individual, la formación (Bildung), no sólo es imitación de la Naturaleza en lo que tiene de venerable, sino su retoque o perfeccionamiento "cuando procura evitar sus crueles e implacables envites transformándolos en algo beneficioso al cubrir con un velo las manifestaciones de sus propósitos de madrasta y de su triste locura» ${ }^{110}$. Sin la cultura, sólo tenemos el sufrimiento del querer ciego e insaciable de una Voluntad que, en el ámbito de la apariencia, es decir, en el de su fragmentación en una multiplicidad de individuos, se intensifica en la implacable lucha de todos contra todos por la conservación y la hegemonía.

Cabe una última consideración sobre la crítica de Nietzsche a la modernidad que implica remitir esta obra a El nacimiento de la tragedia. Si se amplia la perspectiva histórica, nos encontramos con el problema del «origen» de la enfermedad moderna. ¿De dónde procede la modernidad, cual es el linaje al que pertenece, de qué acontecimientos y en qué sentido es resultado? Si antes he interpretado la "metafísica de artista» de El nacimiento de la tragedia desde esta Intempestiva, responder a estas preguntas obliga a cambiar la dirección de la mirada y a situar la crítica a la modernidad de la Tercera consideración intempestiva bajo el horizonte histórico dibujado en El nacimiento de la tragedia. El parágrafo dieciocho de esta obra es una referencia decisiva para comprender la elaboración de lo que G. Vattimo ha llamado «la arqueología de la civilización occidental» ${ }^{111}$. Arqueología o proto-genealogía, en ella se interpreta la totalidad del proceso civilizatorio de Occidente y lo que significa la modernidad para este proceso. Allí Nietzsche afirma lo siguiente: «Todo nuestro mundo moderno está preso en la red de la cultura alejandrina y reconoce como ideal el hombre teórico, el cual está equipado con las más altas fuerzas cognoscitivas y trabaja al servicio de la ciencia, cuyo prototipo y primer antecesor es Sócrates» ${ }^{112}$. Allí también Nietzsche sostiene que la modernidad, en tanto que consumación y final del proceso que comienza en Sócrates y que ha presidido el curso de la civilización occidental, ha de perecer como cultura a causa del estallido de dos contradicciones, una teórica y otra práctica, que ha portado este proceso en su seno desde el principio. Y en la autodestrucción de la cultura socrático-alejandrina, que se produce en la modernidad en la medida que representa su plena realización, se gesta no sólo la posibilidad de la barbarie, sino también la del renacimiento de la cultura trágica, «cuya característica más importante es que la ciencia queda reemplazada, como meta suprema, por la sabiduría ${ }^{113}$. Si Sócrates se hace definitivamente carne en la Época Moderna, «el mito de la Razón», o «el espíritu de la ciencia», es decir, los presupuestos metafísico-morales que sostienen la cultura socrático-alejandrina y han impulsado su despliegue hasta el punto crítico que supone la modernidad, se reconocen como «mitos», como «ilusiones», ya no como «la verdad», y, con ello, se autoaniquilan, pereciendo esta cultura al que-

110. SE, KSA I 341.

111. G. Vattimo, El sujeto y la máscara, Barcelona: Península, 1989, p. 22.

112. GT, KSA I 116.

113. GT, KSA, I 118. 
dar irremediablemente quebrado su fundamento ${ }^{114}$. La alianza entre la Verdad y el Bien, principio supremo de esta cultura racionalista, optimista y universalista, perece a manos de los propios mecanismos que generó, que acaban desvelándola como mentira. La modernidad representa este espectáculo de autonegación de la cultura socrático-alejandrina en el momento en el que alcanza su consumación. La ciencia se vuelve contra su fundamento, destruyendo el mito que la había impulsado, y la realización de los ideales prácticos de la razón, o sacan a la luz su mentira, o la cultura que los tiene como soportes imprescindibles «se encamina poco a poco hacia una aniquilación horripilante» ${ }^{115}$. Por todo ello, la modernidad es para Nietzsche o la antesala de la barbarie o la posibilidad de un renacimiento del ser humano y de la cultura (trágica). El desencantamiento del mundo no nos deja otra salida. Los tiempos están maduros para una inercia que nos devuelve a nuestra animalidad racional o para una acción transfiguradora de la vida y del mundo del hombre, redentora de la Naturaleza, que no sólo exige una transformación de los que han llegado a conocer, por influencia de Schopenhauer o por otras razones, sino también «la lucha en pro de la cultura y la hostilidad contra influencias, costumbres, leyes, disposiciones en las que no se reconozca el propósito que la alienta: el engendramiento del genio» ${ }^{116}$. Y en esa hostilidad contra leyes y costumbres contrarias al genio y a la cultura se encuentra la razón de la crítica política a la modernidad y de la necesidad de un «política trágica».

\section{MODERNIDAD: ATROFIA O HIPERTROFIA DEL ESTADO}

A principios de 1873, Cosima Wagner recibe un presente navideño de Nietzsche, un manuscrito titulado Cinco prólogos para cinco libros imposibles de escribir. Uno de ellos es El Estado griego. Este prólogo es una reproducción casi literal de un fragmento póstumo de 1871 titulado «Fragmento para una ampliación de El nacimiento de la tragedia» ${ }^{117}$. Este fragmento, junto a otros cuantos escritos en estas fechas, forma parte de un material que versa sobre cuestiones políticas. Más concretamente, sobre la relación entre la política y el genio, la política y la cultura y, en último término, la política y la filosofía trágica. Sin embargo, nada de este material, tampoco su pieza más sobresaliente, que es este texto, aparecerá en El nacimiento de la tragedia, el libro al que presumiblemente estaba destinado. No sabemos por qué Nietzsche no lo incluyó en su primera obra publicada, aunque hay indicios sobre dónde tendría que haber sido colocado en ella: allí donde Nietzsche habla de la contradicción práctica de la cultura socrático-alejandrina,

\footnotetext{
114. Repárese en la semejanza entre esta interpretación de la historia de Occidente, entendida como un proceso de progresiva ilustración que culmina en la modernidad, y la de Max Weber, para quien lo característico y distintivo de la civilización occidental es el hecho de que ha transcurrido por una senda de progresiva racionalización, culminando en el «desencantamiento del mundo» que se produce en la época moderna: cf. M. Weber, Ensayos sobre la sociología de la religión, Madrid: Taurus, 1984, vol. I, pp. 11-20.

115. GT, KSA I 117

116. SE, KSA I 386.

117. Cf. NF, KSA VII 333-349.
} 
que promete quimeras como la «dignidad del hombre» y la «dignidad del trabajo", aunque, como toda cultura, ha de sostenerse en un estamento de escla$\operatorname{vos}^{118}$. El fragmento mencionado, precisamente, comienza refiriéndose a esos dos «conceptos-alucinaciones» que caracterizan a los modernos: «Nosotros, los modernos, aventajamos a los griegos con dos conceptos que, en cierto modo, se dan como un medio consolador de un mundo que se comporta absolutamente como un esclavo y que, al mismo tiempo, teme angustiado a la palabra 'esclavo': hablamos de la 'dignidad del hombre' y de la 'dignidad del trabajo'» ${ }^{119}$. En cualquier caso, Nietzsche lo desestimó, a pesar de lo cual no es en absoluto irrazonable, sino más bien todo lo contrario, considerar que El Estado griego es la política oculta de El nacimiento de la tragedia.

El título de este escrito póstumo puede inducir a confusión. Ni pretende describir la organización político-social de su Grecia amada, ni tampoco un retorno político a esa Grecia. Tanto en la política como en cualquier otro aspecto más destacado, para Nietzsche no hay vuelta atrás. No cree en el mito de la Edad de Oro. Tiene suficiente «sentido histórico» para no caer en tales ilusiones. Si la política griega ejerce sobre él un permanente magisterio, porque «la organización más afortunada y agradable de la situación político-social es en los griegos donde se encuentra» ${ }^{120}$, lo hace no en el sentido de repetir en su época lo que fue en ese pasado admirado, sino en el de interpretar el pasado desde su actualidad y en juzgar la actualidad desde el pasado así interpretado. La apropiación de la enseñanza griega no es repetitiva, sino creativa: se trata de recrear, bajo las condiciones de su época, la sabiduría política que se mostró por primera vez con los griegos. En realidad, El Estado griego es una crítica política a la modernidad, más concretamente a la indigencia política que la Época Moderna nos revela cuando se la compara con el mundo griego.

Este texto puede resultar «directamente repulsivo», como le parece a C. P. Janz en su meritoria biografía de Nietzsche ${ }^{121}$. Pero aunque suscite repulsión o rechazo, no deja de ser un escrito fundamental para entender el pensamiento político del joven Nietzsche y del Nietzsche posterior. Podemos aducir tres razones para justificar esta valoración. En primer lugar, este breve escrito muestra la conexión necesaria dentro de su filosofía entre su metafísica de la cultura y la política. En segundo lugar, en él expone, bien que de un modo muy esquemático y general, sus ideas políticas básicas y, además, a través de la crítica de las principales ideologías modernas (liberalismo, socialismo y nacionalismo político), su lucha contra la política de su época. Por último, El Estado griego ofrece las coordenadas políticas fundamentales que se mantendrán más o menos constantes a lo largo de toda su obra. El horizonte de su política, marcado por una concepción aristocrática, se dibuja por primera vez en este escrito y, a pesar de las profundas modificaciones que se operan en el desarrollo de su pensamiento, dicha concepción no sufrirá en términos generales cambios esenciales.

En El Estado griego aparecen entremezcladas las dos cuestiones principales que centran la atención de Nietzsche: la crítica política a la sociedad moderna

118. Cf. GT, KSA I 117.

119. CV, KSA I 764.

120. NF, KSA VIII 33.

121. C. P. Janz, F. Nietzsche, Madrid: Alianza, 1981, vol. II, p. 184. 
y el esbozo de una idea del Estado. Y ambas se plantean mediante la comparación con el paradigma griego. El comienzo de este escrito no sólo señala esta forma de proceder comparativa, sino también dos cosas más: el estilo directo, agresivo y polémico que se mantendrá hasta el final, y, sobre todo, la crítica de dos valores que, en gran parte, sustentan el edificio de la sociedad moderna. El hombre moderno se distingue del griego porque necesita de dos conceptos - tildados de alucinaciones por Nietzsche - desconocidos por aquél: la «dignidad del hombre» y la «dignidad del trabajo». Mediante ellos, Nietzsche nos señala la insuficiencia y el carácter defectuoso de la política moderna. El extravío de la política de los modernos consiste en «las atrofias peligrosas de la esfera política, igual de graves para el arte como para la sociedad» ${ }^{122}$. La hegemonía de los conceptos «dignidad del hombre» $\mathrm{y}$ «dignidad del trabajo» en el discurso político moderno nos remite a las dos fuerzas que, ligadas, son responsables de esta atrofia perniciosa: una determinada concepción de la moral y una de la economía. En su relación con la política, tanto el «moralismo» implícito en el concepto de «dignidad humana» y en la fraseología falaz de «los derechos del hombre y del ciudadano» que lo acompaña, como la autonomía y la preponderancia de los valores e instituciones económicos en la moderna sociedad industrial, son los dos factores limitativos y astringentes que producen la debilidad constitutiva de lo político en la Época Moderna.

Lo político queda neutralizado ${ }^{123}$; de este modo, se desnaturaliza, no pudiendo desempeñar las funciones que debe cumplir. Para quebrar la hegemonía de la moral y de la economía y para rehabilitar la política, Nietzsche propone dos medidas brutales: la guerra y la esclavitud. Éstas son dos medios excelentes, los mejores, si el problema fundamental de la política moderna estriba, como Nietzsche piensa, en la reconducción adecuada de la misma hacia los fines a los que debe servir. Esta reconducción implica la transferencia del predominio de la moral y la economía a la política, y la subordinación de ésta a la cultura, convirtiéndola en un medio para la producción, conservación y hegemonía del genio. Con el objeto de lograr esto, la guerra, indudablemente, es una buena medida: destruye la estabilidad de los mercados nacionales e internacionales y transforma las economías nacionales en economías de guerra, con todas las intervenciones en la producción y en el mercado que ello supone, impidiéndose, así, lo que Nietzsche denomina la «racionalización» del Estado, y supeditándose la economía a la política. A su vez, la guerra cumple una buena función en el desenmascaramiento de los intereses «demasiado humanos» que encubren expresiones como «dignidad humana», «derechos del hombre» y similares. Y la esclavitud también lo es: concíbase ésta de un modo u otro, pues Nietzsche no deja claro lo que entiende por esclavitud, mediante ella se vuelve a introducir el principio jerárquico en la sociedad, se rehabilita un orden social basado en el «estatus» y no en el «contrato»y, de nuevo, se supedita la economía a la política o al Estado. Toda organización político-social adecuada para cumplir los fines culturales a los que debe servir, como nos enseña el ejemplo de la sociedad griega, refleja el

122. CV, KSA I 772.

123. Sobre el concepto de neutralización, cf. C. Schmitt, «La época de las neutralizaciones y despolitizaciones» (Der Begriff des Politischen, München/Leipzig: Duncker \& Humblot, 1932, pp. 66-81). 
conocimiento de que «la guerra es para el Estado tan necesaria como el esclavo para la sociedad $»^{124}$.

La primacía de lo económico y la moral de la «dignidad humana» como fundamento de la política son los rasgos esenciales que presenta el semblante político de los modernos. Ambos hechos son la causa de la atrofia de lo político y el obstáculo para el desarrollo de una «política trágica» que devolvería a la política el lugar y la dignidad que le corresponde. El producto específicamente político de la preponderancia de la peculiar conjunción de la economía y la moral en la época moderna es, desde el punto de vista ideológico, la hegemonía de «la concepción del mundo liberal-optimista» ${ }^{125}$; y, en el plano institucional, la implantación progresiva y arrolladora de la democracia liberal. El origen histórico de ambos se encuentra en la Ilustración francesa y la Revolución, que representan para Nietzsche «una filosofía superficial y sin metafísica, absolutamente antigermánica y genuinamente latina» ${ }^{126}$. Estos acontecimientos históricos configuran el horizonte político de la modernidad desde el punto de vista ideológico. El liberalismo, el socialismo y el nacionalismo político, las concepciones predominantes en el siglo XIX, son sus retoños. Al menos las dos primeras, y algunas variantes de la tercera, convergen en un punto: la primacía de la sociedad civil en su relación con el Estado, la pérdida de sustancia del Estado, el triunfo de lo económico sobre lo político. De hecho, la difusión de la concepción liberal del mundo, con sus principios morales y políticos basados en la «dignidad del hombre», es interpretada por Nietzsche como el instrumento ideológico adecuado de la burguesía, o de la «alta burguesía», para justificar su papel dominante en la sociedad y para poner al Estado al servicio de sus intereses. La aspiración de la burguesía a ejercer un dominio completo y a convertir al mundo en un ingente mercado es el interés oculto que fomenta la ideología liberal, y, de ahí, su apelación a la guerra como medio de ruptura del mundo liberal ${ }^{127}$.

Dicho esto, se trata ahora de comprender las razones por las que el Estado liberal y la primacía de la sociedad civil que le distingue impiden la aparición de las condiciones que se precisan para la creación de lo que el Nietzsche de la metafísica de artista llama «Estado de cultura» ${ }^{128}$ y de la sociedad trágica correspondiente. Si consideramos sus principios políticos fundamentales y característicos los siguientes: la soberanía limitada; la defensa de los derechos y libertades fundamentales y del «imperio de la ley», que son los factores jurídicos que limitan el ejercicio del poder soberano; la división de poderes y el lugar privilegiado que ocupa el poder

124. CV, KSA I 774.

125. CV, KSA I 773.

126. Ibid. En esta valoración negativa de la Ilustración y la Revolución nos encontramos como telón de fondo la oposición cultura/civilización que recorre todo su pensamiento de juventud: cf. GT, KSA I 146-147; DS, KSA I 159-164; HL, KSA I 275, y BA, KSA I 690.

127. Nietzsche lo expresa de esta forma rotunda y directa: «Si, por consiguiente, yo señalo como característica peligrosa del presente político el uso del pensamiento revolucionario al servicio de una egoísta aristocracia del dinero sin Estado: si yo, al mismo tiempo, comprendo la propagación del optimismo liberal como el resultado de la economía financiera moderna, caída en manos extrañas, y descubro que todo mal de las condiciones sociales, junto a la decadencia necesaria del arte, brota de esta raíz o se entrelaza con ella, entonces se me tendrá que aceptar que entone esporádicamente un peón a la guerra» (CV, KSA I 774).

128. NF, KSA VII 143. 
legislativo, depositario de la soberanía nacional; y, por último, la neutralidad del Estado respecto a las concepciones de bien de los ciudadanos que consienten en su autoridad. Y si también consideramos que su defensa de la autonomía de la esfera económica, garantía fundamental de la subordinación del Estado a la sociedad civil, tiene como consecuencia no sólo el aseguramiento de la libertad individual y la política, sino una distribución óptima de los recursos que garantiza el mayor grado posible de felicidad y bienestar general de la sociedad, y subsecuentemente de los miembros que la forman, entonces, considerando todo ello, la sociedad política moderna, atrofiada y liberal, es el principal enemigo a batir y el mayor obstáculo para la instauración en la sociedad de una política y un Estado trágicos. Comprender este enfrentamiento inconciliable en su justa medida obliga al intérprete a dejar de lado el aspecto crítico de su pensamiento político y a pasar a su dimensión positiva que, en este escrito, se centra en la cuestión del Estado.

La cultura y la política para el joven Nietzsche, su concepto de cultura trágica y de Estado trágico, reciben su luz peculiar del substrato metafísico en el que se enraízan, y que Nietzsche denominó, como ya hemos señalado anteriormente, «metafísica de artista» ${ }^{129}$. Así como es difícilmente inteligible su concepto de cultura sin atender a su "significación metafísica», así también sucede con su concepto de Estado. Por ello es conveniente empezar por su significado metafísico.

La Voluntad, que es el modo como la metafísica de artista interpreta la Naturaleza, tiene, como el dios Jano, un doble rostro: el dolor y el sufrimiento producidos por su ciego querer, y el placer y la belleza generados por su capacidad artística redentora. Ambos son indisociables, no existen el uno sin el otro, no puede ser uno eliminado en beneficio del otro, y el mundo, que es manifestación de la Voluntad y juego de la Voluntad consigo misma, se interpreta como una relación conflictiva entre los dos «atributos» de la Voluntad, entre lo dionisíaco y lo apolíneo. Todo lo que existe participa del juego de estas dos potencias, porque todo es Voluntad; en consecuencia, todo es querer esencial y apariencia redentora. La vida es, a la vez, un espectáculo salvaje y placentero, un proceso inagotable en el que el conjunto de lo viviente se encuentra afectado por la trabazón indisoluble entre la brutalidad y el dolor causado por la implacable lucha por la existencia y el placer generado por la bella apariencia. Y el hombre no es una excepción, comparte con todo lo vivo el hecho de ser una voluntad fiera, hambrienta e implacable que quiere conservar su existencia a costa de todo lo demás y el hecho de ser una apariencia que forma parte del teatro del mundo creado por la Voluntad para su deleite. Sin embargo, a diferencia del resto de los seres, posee la capacidad, como fenómeno e instrumento de la Voluntad, de crear apariencias, de forjar un mundo de ilusiones que constituye la cultura. Gracias a ésta, el hombre puede vivir; y gracias a ésta, concretamente en una determinada configuración de la apariencia producida por el genio (la tragische Daseinform), la Naturaleza o la Voluntad se perfecciona y alcanza el estado de transfiguración en el que se reconoce a sí misma a través de la mediación simbólica de la pura apariencia artística.

Esta es otra versión comprimida, desde El nacimiento de la tragedia, de la metafísica de artista. ¿Qué decir, a partir de aquí, del Estado? Pues que el Estado, 
como mecanismo sumamente artificial creado por el hombre y teniendo a Apolo como padre fundador, también tiene un doble rostro, un doble origen, una doble condición, un doble sentido. Empíricamente, como fenómeno histórico, aparece como una maquinaria brutal, una ciega concentración de fuerzas cuyo origen es la violencia, cuya vida representa la lucha por la existencia y por el predominio en su máxima y más abominable expresión, y cuyas consecuencias son el horror y la destrucción. La caracterización de Nietzsche no puede ser más elocuente: «El Estado, de origen indigno, es una fuente de penas para la mayoría de los hombres que fluye continuamente, la antorcha que, en períodos que se repiten con frecuencia, devora al género humano» ${ }^{130}$. Pero desde un punto de vista metafísico el significado del Estado es otro muy distinto. Platón, como señala Nietzsche al final del texto ${ }^{131}$, en una infrecuente valoración positiva de su pensamiento, supo captar este sentido esotérico del Estado, a saber, la oculta conexión entre la política y el arte, entre el Estado y el genio. Metafísicamente considerado, la causa del Estado radica en el «instinto de Estado» ${ }^{132}$ que posee la Naturaleza; su carácter es el de ser un instrumento necesario para, mediante la sociedad, crear las condiciones que permitan el florecimiento, la conservación y la primacía del genio; y su finalidad, que justifica su dimensión horrorosa, es la misma que la de la Naturaleza: la epifanía del genio mediante la cual puede lograr su redención. El genio es el medio de la Naturaleza para lograr su transfiguración y el Estado el medio imprescindible para que el genio pueda cumplir su cometido. Como afirma en el texto, tanto el horror del Estado, como el hecho de que los hombres lo encubran con elevadas ficciones éticas, "nos habla de la tremenda necesidad de Estado, sin la cual no tendría éxito la naturaleza en el intento de alcanzar, a través de la sociedad, su redención en la apariencia, en el espejo del genio» ${ }^{133}$. El Estado es, como sostiene en otro fragmento póstumo, de acuerdo con su última meta, «un establecimiento de asistencia y protección para el individuo, por poco que indique tal meta el origen cruel y la conducta bárbara del mismo» ${ }^{134}$. Y quizá, en el mismo póstumo, Nietzsche consigue expresar de un modo categórico la verdadera naturaleza del Estado y el propósito oculto que explica su necesidad y justifica su condición horrorosa: «Para que el artista pueda formarse, necesitamos aquel estamento ocioso liberado del trabajo de esclavos: para que pueda originarse la gran obra de arte, necesitamos la voluntad de aquel estamento, al Estado» ${ }^{135}$.

Si nos preguntamos por la necesidad que la Naturaleza tiene del Estado, la respuesta se encuentra en la dimensión horrorosa de su ser y en las consecuencias que de esto se deriva para el mundo, en especial para el mundo humano. La Naturaleza, interpretada como Voluntad, crea el mundo como proyección artística para redimirse de la contradicción y el dolor originarios que padece. Pero esta creación implica su fragmentación en una multiplicidad de centros volitivos en continua pugna, conflicto y lucha entre sí por la conservación y el predomi-

130. CV, KSA I 771.

131. CV, KSA I 776-777.

132. CV, KSA I 773.

133. CV, KSA I 770-771

134. NF, KSA VII 168.

135. NF, KSA VII 169. 
nio. La lucha por la existencia es por lo tanto un factum irreductible, un motivo permanente del obrar de individuos, pueblos y Estados. Por razones ontológicas, la condición «malvada» que la vida humana comparte con la vida en general no puede ser eliminada o superada, encontrándose aquí el rasgo característico de una concepción pesimista y trágica del mundo. La naturaleza del poder «siempre es mala» ${ }^{136}$, dice Nietzsche. Sí, pero hay que agregar que el poder es necesario. En consecuencia, los males políticos y sociales, la injusticia y la opresión, la explotación y el imperio de la fuerza, son hechos que siempre acompañarán a la vida humana. Éste es el verdadero núcleo del «realismo político» de Nietzsche, una constante en toda su obra modulada de diferentes maneras.

Pero sobre este fondo horroroso se distingue la necesidad que tiene la Naturaleza, mediante el genio y su producción cultural, de esa apariencia elevada a segunda potencia que es el arte para su transfiguración, para su redención suprema. Por ello se precisa la utilización y la orientación adecuada de la condición malvada del ser humano: no puede ser extirpada, pero sí dirigida, bien por esa extraña «astucia de la Voluntad» llamada «instinto de Estado», bien porque se eleve a consciencia una vez conocida la finalidad de la Naturaleza y se actúe políticamente en consecuencia; y así puede ser conducida de tal modo que logre la realización del mundo de la cultura y la hegemonía del genio. Atendiendo a esta realidad positiva y ontológicamente determinada del mal, cuando se transpone a la sociedad y a la política, se «justifica» la afirmación categórica de que «la esclavitud pertenece a la esencia de una cultura» ${ }^{137}$ y de que la guerra es un ingrediente necesario del Estado.

Sin el Estado, no es posible la aparición y la supervivencia de una sociedad suficientemente compleja y desarrollada que permita «el nacimiento continuamente doloroso de aquellos eximios hombres de cultura» ${ }^{138}$. Sin su fuerza coactiva y su voluntad concentrada, los privilegios que requieren los hombres excepcionales, la «aristocracia espiritual», no pueden ser mantenidos. Sin la organización estatal, el genio y la cultura no se producirían porque, en primer lugar, los conflictos y las perpetuas luchas entre los individuos destruirían el orden y la estabilidad social que precisa el genio para su existencia y su reproducción; y, en segundo lugar, algo más decisivo aún, no sería concebible la división social del trabajo que hace posible la existencia «parasitaria» del genio y la producción de la cultura. Sin el poder del Estado, ni la sociedad estaría protegida de las agresiones externas, ni se incrementarían los recursos materiales e intelectuales de la sociedad, ni la esclavitud sería posible. Y sin la existencia de estas condiciones, el genio nacería muerto. Estas razones, y algunas otras más que se podrían aducir, explican la necesidad del Estado. Y todas ellas apuntan a la principal: sin el poder soberano de un Estado que, consciente o inconscientemente, tenga en la cultura y el genio su fin supremo y su última justificación, la Naturaleza nunca lograría alcanzar la meta que tan torpemente anhela. De este modo, Nietzsche no sólo justifica la necesidad de la política, sino que establece el lugar y la función que ocupa dentro de su filosofía: es un medio necesario para la realización de sus fines y, como tal, subordinado a ellos y por ellos legitimado.

136. CV, KSA I 768.

137. CV, KSA I 767.

138. CV, KSA I 769. 
No obstante, aunque la naturaleza posea un «instinto de Estado», también es ciega, torpe, incapaz de gestionar racionalmente sus recursos de acuerdo con sus fines. Su propósito late en lo oculto, razón por la cual, como la historia de la humanidad demuestra, queda sistemáticamente frustrado. Por ello, para ayudar a la Naturaleza, para corregir su «insensatez», se precisa para Nietzsche convertir en consciente la inconsciente teleología de la Naturaleza. De no ser así, el fin puede ser manipulado y convertido en medio de otros fines que nada tienen que ver con la cultura y el genio. Cómo ocurre tal cosa con la cultura nos lo ha señalado Nietzsche con todo detalle en la Tercera consideración intempestiva, como hemos indicado en el apartado anterior: el fin supremo de la existencia queda rebajado a medio del Estado, del afán de riquezas, de la ciencia o, simplemente, de la superficialidad y futilidad de una vida dominada por el tedio.

La crítica a la política moderna en este texto muestra también claramente no sólo la necesidad de conocer la meta de la Naturaleza, sino también de hacer consciente el «instinto de Estado», o el hecho de que la política debe ser un instrumento para la realidad del arte y el florecimiento del genio. En caso contrario, este medio puede ser utilizado para otros fines, o puede, fraudulentamente, hacerse pasar por el fin último. La primera posibilidad es la que denuncia $E l$ Estado griego: la atrofia política de la sociedad moderna supone que el Estado, reducido el ámbito de aplicación de su poder, se utiliza para un fin distinto al que debe servir. El Estado liberal no pretende la promoción del genio, sino tan sólo, como instancia de arbitraje, la protección de los derechos y de los intereses legítimos de los ciudadanos. Lo que para Nietzsche esto significa en realidad es el hecho de que el Estado se convierte en un medio para la promoción de las metas egoístas y el enriquecimiento de la minoría que disfruta del poder económico dentro de la sociedad.

La otra posibilidad, no menos peligrosa, la señala en otros lugares. En este caso, la perversión del «instinto de Estado» consiste en la hipertrofia de la esfera política: el impulso político, que debe agotarse en la «conservación de la cultura» ${ }^{139}$, ensancha su dominio, y de servidor pasa a ser el amo. El Estado se impone como valor supremo al que se debe servir incondicionalmente. Buscando solamente el aumento de poder sin límites, consumirá a la sociedad absorbiendo todas sus energías, incluyendo también aquellas que son vitales para el genio y la cultura. Este es el caso de Roma para este Nietzsche: comparado con los griegos, el Imperio romano sólo es una ingente construcción de fuerza bruta y un yermo cultural ${ }^{140}$. Y también en su época Nietzsche detecta esta tendencia en el Segundo Reich alemán. En el primer parágrafo de la Primera consideración intempestiva denuncia el peligro de que el maltrecho espíritu alemán quede devorado por el naciente Imperio alemán ${ }^{141}$.

A tenor de lo expuesto, la justificación cultural y filosófica del Estado que lleva a cabo Nietzsche exige a la realidad estatal unas características que contravienen los principios políticos de libertad e igualdad en los que se funda tanto la mayoría de los elementos del espectro ideológico de su época como, aunque sea de forma insuficiente o muy limitada, las sociedades políticas más avanzadas del

139. NF, KSA VII 142.

140. Cf. GT, KSA I 133, y NF, KSA VII 149.

141. Cf. DS, KSA I 159-160. 
siglo xIx. Frente a un Estado legitimado por el valor «libertad», que se traduce constitucionalmente en la garantía de los derechos y libertades fundamentales de los ciudadanos y en la libertad política, lo que caracteriza al «Estado de cultura» pensado por Nietzsche es su condición marcadamente autoritaria. Por otro lado, frente a un Estado también legitimado por el valor «igualdad», entendido éste como igualdad jurídica, para el filósofo alemán la estructura estatal ha de ser jerárquica, en el preciso sentido de prescribir la desigualdad de los individuos ante la ley y en consecuencia negar el principio de igualdad jurídica. "Autoritario» y «jerárquico» son los atributos que convienen al «Estado de cultura» pensado por Nietzsche, cuya legitimidad descansa en su adecuación como medio del fin perseguido por la Naturaleza: la promoción de la cultura y la producción, conservación, reproducción y predominio de los hombres excepcionales, del genio. Lo que de acuerdo con tal fin «prescribe la Naturaleza» o «dicta la vida» como norma suprema, que caracteriza su «aristocratismo político» y lo enfrenta al mundo político moderno, puede encontrarse en estas palabras de El Estado griego: "Cada hombre, con toda su actividad, tiene tanta dignidad en tanto en cuanto sea, consciente o inconscientemente, un instrumento del genio; de lo que ha de extraerse inmediatamente la consecuencia ética de que el 'hombre en sí', el hombre absoluto, no tiene dignidad, ni derechos ni deberes» ${ }^{142}$.

Franz Overbeck, el amigo de Nietzsche que fue a Turín a recogerlo después de su desplome psíquico, observa con agudeza en unas notas en las que recoge sus recuerdos del filósofo que Nietzsche ignora la religión, tanto en sí misma como en su relación con él, «porque ha tenido mucho que ver con la cultura, un concepto más amplio por cuanto encierra en sí mismo la religión como uno de los instrumentos de la propia cultura que el hombre tiene en su poder» ${ }^{143}$. Algo parecido puede afirmarse del joven Nietzsche y de su crítica a la modernidad: ésta, sin duda, es esencialmente cultural, pero requiere también el acompañamiento de la confrontación política con el mundo moderno. En sí misma, la "política» carecía de interés para él o, en todo caso, éste era muy secundario; pero como medio imprescindible para la realización del ideal de cultura trágica, la crítica política y el esbozo de una teoría política cumplen un papel necesario en su pensamiento, captando de este modo subsidiario su atención.

142. CV, KSA I 776.

143. F. Overbeck, La vida arrebatada de F. Nietzsche, Madrid: Errata naturae, 2009, p. 58. 